\title{
Factors Influencing Increases in Residential Recycling System Costs for Ontario's Blue Box program
}

\section{Calvin Lakhan*}

Department of Geography, Wilfrid Laurier University, Waterloo, Ontario, Canada

\begin{abstract}
This study undertook an extensive overview of the state of recycling in Ontario, including detailed discussions on the types of material being generated and diverted and the economics of Blue Box recycling. Specifically, this study examined how Blue Box generation, recovery and costs have changed over time, and identified trends in the data to suggest that material management costs are increasing inordinately relative to the quantities of material being recovered. While it is difficult to specifically isolate the cause for rising system costs, there is evidence in the data to suggest that high cost "fringe" materials now comprise a larger share all material being generated in the province. Given that there is strong statistical support to suggest that this trend is likely to continue into the future, policy planners need to take a step back and identify not only how to reverse these trends, but develop policies that optimize the mix of materials being recovered.
\end{abstract}

Keywords: Recycling; Extended producer responsibility; Cost containment; Diversion

\section{Introduction}

One of the foremost challenges with developing sustainable waste management systems is the cost of implementation. The infrastructural and operational costs of building and maintaining an integrated waste management system (ISWM) is prohibitive to some municipalities in the absence of cost recovery schemes (extended producer responsibility programs), collecting, processing and safely managing end of life packaging waste can comprise a significant portion of municipal budgets. While ISWM principles emphasize that a waste system should be economically affordable as well as environmentally sustainable, the two are often (but not always) dichotomous pursuits. When compared to conventional land filling and incineration, recycling and waste diversion is a costly endeavor [1]. To help illustrate this point, let us briefly consider the Ontario Minister of the Environment's (MOE) decision to increase provincial recycling targets for the province's residential recycling program (Blue Box).

In 2011, the MOE recommended a provincial recycling rate target of $70 \%$ for all residential recyclable material. This move was heralded as a "step in the right direction towards a more sustainable Ontario" and largely applauded by both municipal officials and the general public. For the better part of three decades, recycling has been a cornerstone of the province's sustainability strategy and is seen as a key driver towards a "closed loop economy". However, the emphasis placed on increasing the provincial recycling rate has come at an enormous financial cost to both municipalities and industry.

In Ontario, the generation of total recyclable material (per annum) has increased from $1,211,000$ tonnes to $1,386,000$ tonnes between the periods of 2002 and 2012 [2]. The costs of managing this system have increased by $78 \%$ during this same period [3]. Both packaging producers and municipalities have expressed extreme concern over the inordinate rise in system costs relative to the increase in waste diversion [4]. At this juncture, there remains considerable debate surrounding why material management costs have increased (where material management costs are defined as the costs incurred for collecting, processing and providing administrative support for recycling waste). Increases in costs have been attributed to decreased revenue from the sale of recyclable material, an increasing trend for producers to switch to "light weight" packaging, and inefficiencies in municipal waste collection and processing. However, no study to date has attempted to empirically examine whether any of these potential explanatory factors have merit. This study attempts to explain changes in Blue Box system costs and recycling rates by:

1) Examine how material specific generation, recovery and revenue has changed over time, attempting to identify any patterns in the data

2) Examine how the composition of the Blue Box has changed over time in an attempt to explain whether changes in system costs are attributable to the change in the mix of materials being recovered

3) Examine how the costs of material management for the Blue Box recycling program has changed over time

As far as can be ascertained, this is the first study of its kind to specifically isolate why Blue Box system costs have changed by reviewing panel data for the program spanning the past decade.

\section{Literature review}

As noted by Ref. [5], there is a general consensus in the literature that the direct costs of recycling exceed the costs of disposal. Work by Ref. [6-8] all notes that reported municipal recycling costs for household waste are greater than the costs of disposal. However, there are two issues with this claim:

1) When externalities are factored into the cost of recycling (relative to the costs of disposal), there is significant evidence that suggests recycling is economically and environmentally preferable [9].

*Corresponding author: Calvin Lakhan, Department of Geography, Wilfrid Laurier University, Waterloo, 21st Madrid Crst, Brampton Ontario, L6S2X, Canada, Tel: 3288-5198840710; E-mail: lakh2440@mylaurier.ca

Received January 21, 2016; Accepted January 29, 2016; Published February 07, 2016

Citation: Lakhan C (2016) Factors Influencing Increases in Residential Recycling System Costs for Ontario's Blue Box program. Adv Recycling Waste Manag 1: 103. DOI: 10.4172/2475-7675.1000103

Copyright: (c) 2016 Lakhan C. This is an open-access article distributed under the terms of the Creative Commons Attribution License, which permits unrestricted use, distribution, and reproduction in any medium, provided the original author and source are credited. 
2) The costs of recycling can be reduced through policies such as unit based pricing on garbage disposal see works by Ref. [1016], and policies to encourage cost containment [17]. In several instances, reductions in the cost of recycling make it a cost competitive alternative to disposal $[18,19]$.

The consideration of externalities (both economic and environmental) is critical when evaluating the merits of recycling initiatives. Most of the literature in favor of recycling cite the benefits of reducing the need to procure material from virgin sources [20]. This has obvious environmental benefits, in that depending on the material being recovered, recycling can reduce emissions output by a factor of 10x [20,21]. Furthermore, recycling is seen as promoting resource stewardship and helps preserve declining resource stocks. Increased recycling also reduces the quantities of material being sent to landfills, reducing the strain on landfill capacity and the need to site new landfills (which is becoming increasingly difficult in urban areas). In Ref. [22] Even argue that the cost of recycling decreases relative to disposal over time, as landfill costs will increase as available capacity decreases. Studies conducted by the Conference Board of Canada [23], the National Recycling and the [20] also find that recycling activity contributes to job creation (recycling creates $7 \mathrm{x}$ more jobs when compared to disposal), gross domestic product and value added measures. Even when the jobs displaced from recycling activity are accounted for, recycling positively impacts employment levels and the economy as a whole.

Given the extensive evidence in favor of recycling, why do municipalities struggle with rising material management costs? As noted by Ref. [24], few (if any) recycling systems for household packaging waste are self-sustaining (where the economic benefits of recycling activity offset the cost incurred for material management at the municipal level). Critics of recycling often claim that recycling is an inefficient activity, as it generally costs more to use recycled material relative to procuring virgin material [24]. However, the economic viability of municipal recycling systems is a subject of contention among researchers [24-26]. The costs, benefits and support for recycling range widely across studies. This may be attributed to the site and situation specific factors that ultimately drive the costs of recycling in any given area. Curbside vs. bring/depot systems, regulatory requirements (mandatory recycling schemes vs. voluntary initiatives) and the presence of extended producer responsibility legislation are just some of the factors that affect the costs of recycling. While Ref. [22] argue that the cost of recycling decreases relative to disposal over time (as landfill costs will increase as available capacity decreases), this is predicated on the assumption that landfill space is finite. In a review of Ontario's landfill infrastructure, the exact opposite is actually observed. Due to a trade agreement with the state of Michigan that enabled Ontario to export waste to other jurisdictions, available landfill capacity in the province increased by a factor 10x. As a result, landfill tipping fees decreased by more than $90 \%$, reducing the cost of disposal relative to recycling [27].

The recyclability and cost of managing specific materials also has a significant effect on the economic viability of municipal recycling systems. The tenability of recycling systems is largely dependent on the type of packaging material recycled. In studies by Ref. $[5,28]$, it was found the recycling of packaging with low resale value (and low raw material costs), may not be economically sustainable in the long run. This problem is only exacerbated if the costs of recycling are high, particularly for materials which are also difficult to recycle (i.e. plastic laminants and composite packaging). A notable exception to this issue is metals recycling (aluminum and steel), which has consistently shown positive economic benefits relative to virgin material procurement [29].

This paper does not attempt to offer any definitive guidance regarding the appropriateness of recycling as a sustainability strategy. Instead, it focuses on the possible factors contributing to changes in recycling costs and performance in the province of Ontario. Recycling stakeholders have long postulated about the potential causes for these changes (decreases in material revenue, package light weighting, decline in the use of printed paper etc), but to date, no systematic review has been undertaken to identify whether there are any truth to these assertions. Readers are cautioned from drawing any definitive conclusions regarding why material costs, recovery, generation etc. have changed. The drivers of these factors are complex, interconnected, and often, not readily identifiable. As such, attributing changes to any one source may prove erroneous.

\section{Materials and Methods}

\section{Description of study site}

Ontario remains at the forefront of recycling initiatives and legislation in Canada, recognized as one of only three provinces in Canada to implement an extended producer responsibility scheme(EPR) for household recyclables. Residential and commercial waste diversion programs exist for MHSW (Material Hazardous or Special Waste), WEEE (Waste Electrical and Electronics Equipment), automobile tires, and printed paper and packaging (Blue Box) materials. Each of these programs exist under the oversight of Waste Diversion Ontario, (WDO), a non-crown corporation created under Ontario's 2002 Waste Diversion Act. The WDO was established to develop, implement and manage waste diversion programs for stakeholders from both private and public sectors.

Under provincial regulation O. Reg. 274/04, all producers of printed paper and packaging are required to pay a fee to finance the end of life management of material generated in the province MOE. Producers are financially obligated to contribute $50 \%$ of reported municipal costs for the operation and maintenance of the Blue Box program. Conversely, under provincial regulation O. Reg. 101/94, Every municipality with a population of 5,000 or more residents are obligated to operate a Blue Box program accepting at least five mandatory materials MOE, plus three optional materials. A total of 23 packaging types have been classified as being eligible for inclusion in the Blue Box.

Data for Ontario's residential recycling system was obtained from the Waste Diversion Ontario municipal data call. Each year, the WDO requests that every municipality within Ontario report detailed recycling and cost information regarding the management of their waste diversion programs. Municipalities are required to log into the Waste Diversion Ontario web site and fill out an electronic questionnaire that solicits information that includes information on the amount of material recovered, the types of material recovered and the operating and capital costs associated with the management and collection of recyclables. All data used in this study pertains to printed paper and packaging recyclables found in the residential recycling stream, i.e. newsprint, cardboard, glass, aluminum, steel, composite packaging and plastics.

This section provides a high level overview of how the composition, costs and revenues for Blue Box materials have changed over the past decade. The purpose of this section is to identify trends in the data to project how material costs, revenues and tonnage have changed in the past and may change in the future. For the purposes of this analysis, the 23 Blue Box materials accepted by municipalities have been collapsed 
into 9 like categories. This was done to better facilitate comparisons within material groups and organize the data in a more coherent fashion. Table 1 below summarizes how the material categories were grouped: Data used in this section was obtained from the Stewardship Ontario Fee Calculation Model [30-34] (Hence forth referred to as the Pay In Model (PIM Model)).

Note: While the PIM model files available on the Stewardship Ontario website date back until 2003, it should be noted that the PIM models for years 2003 and 2004 were revised to use the 2005 PIM data. As such, their inclusion is omitted, as the data is identical across all three years. A total of 1208 data points (each representing a material's generation, recovery, revenue and gross cost per tonne) were included in the analysis. Given that some of the materials included in the like categories had different values for revenue and gross costs (i.e. Telephone Directories receive revenue of $\$ 91.61$ per tonne, while Magazines receive a revenue of $\$ 87.95$ per tonne), weighted averages were calculated to reflect these differences (in lieu of taking the straight average of the group, which would not reflect the relative contribution of total tonnage).

\section{History of blue box recycling}

A meaningful examination of solid waste management in Ontario is best informed by the context of its historical evolution. It is as part of this history that the structure, scale and operation of municipal solid waste management (MSWM) systems today may be better understood. The switch from refillables to recyclables beverage containers during the 1980 s resulted in significant increases in household waste generation in Ontario. The infrastructure to collect and manage recyclable containers was still very much in its infancy, and by the late 1980s, Ontario was faced with a looming crisis in landfill capacity Pollution Probe 1997. Despite repeated efforts by the Minister of the Environment (MOE) to abolish the use of non-refillable containers, the beverage industry ultimately prevailed in striking down any proposed legislation. Beverage brand owners threatened job cuts and facility closures if the mandatory use of refillable containers were imposed Pollution Probe, 1997. These threats were taken quite seriously, as the economic recession of the early 1980s forced policy planners to prioritize job preservation.

As a compromise solution, the provincial government drafted Regulations 340 and 357 under the Environmental Protection Act. These regulations were designed to promote recycling, while also trying to ensure that refillable beverage containers would continue to be sold [35]. The regulations initially asked beverage brand owners to voluntarily bottle $40 \%$ of products in refillable container. The remainder could be bottled in any recyclable container, but with a requirement these materials achieve a 50\% recycling rate by December 1988 [35].

\begin{tabular}{|l|l|}
\hline Material Category & Materials Included \\
\hline Newsprint & Newsprint -CNA/OCNA, Newsprint - Non CAN/OCNA \\
\hline Mag, Tel, OPP & $\begin{array}{l}\text { Magazines and Catalogs, Telephone Books, Other Printed } \\
\text { Paper }\end{array}$ \\
\hline OCC \& OBB & Corrugated Cardboard, Boxboard \\
\hline Composite Paper & Gable Top Cartons, Aseptic Containers, Paper Laminants \\
\hline PET \& HDPE & PET Bottles, HDPE Bottles \\
\hline Film, Lam, Poly, OP & Plastic Film, Plastic Laminants Polystyrene, Other Plastics \\
\hline Steel & $\begin{array}{l}\text { Steel Food And Beverage Cans, Steel Aerosols, Steel } \\
\text { Paint Cans }\end{array}$ \\
\hline Aluminum & $\begin{array}{l}\text { Aluminum Food and Beverage Cans, Other Aluminum } \\
\text { Packaging }\end{array}$ \\
\hline Glass & Clear Glass, Colored Glass \\
\hline & Table 1: Blue Box Material Categories. \\
\hline
\end{tabular}

To help achieve this diversion target, the Ontario Soft Drinks Association established Ontario Multi Material Recycling Incorporated (OMMRI), an industry funded organization tasked with funding and developing a curbside recycling program [35]. In 1987, OMMRI pledged 20 million dollars in funding over four years, which was matched by municipalities and the Ontario government to fund the Blue Box recycling program [35]. The development of curbside recycling ultimately proved to be the death knell for Ontario's deposit return system for non-alcoholic beverages. Despite the aforementioned regulatory requirements, the use of refillable containers declined to 3\% by the end of the decade. At the same time, Ontario's curbside recycling program flourished, implemented in over 100 provincial municipalities by 1990 [35].

By the beginning of the 1990s, the Ontario government and the MOE recognized that a deposit return system was unlikely to succeed in the province. Further to that point, household waste generation was at a historical high, while available landfill space was becoming increasingly scarce [35]. As such, the policy focus of the MOE shifted to prioritizing waste diversion and promoting the $3 \mathrm{R}$ platform of "Reduce, Re-use and Recycle". The Minister of the Environment launched the Waste Reduction Action Plan (WRAP) in February of 1991 [35]. The WRAP included a number of initiatives designed to promote waste diversion and the 3Rs. These included: regulatory measures; financial and technical support; public education; and the development of markets for recyclable materials [35]. In Table 2 below summarizes the $3 \mathrm{R}$ regulations that were implemented to further enhance the efficacy of WRAP. O. Reg 101/94 should be seen as a critical development in the evolution of Ontario's MSWM system. Household and municipal participation in recycling was no longer a voluntary initiative, but a legislative requirement. In many ways, Reg 101/94 symbolized Ontario's commitment to recycling as a core element of the province's sustainability strategy. The effects of the regulation were immediate, with the province's diversion rate increasing by $5 \%$ in the following year Pollution Probe in 1997. Despite the successes of the Blue Box program, funding the recycling system remained a significant challenge. Revenue from recyclable material failed to meet expected levels, while the amount of material being managed by the residential recycling system increased by $50 \%$ over an eight year period (1990-1998) Stewardship Ontario, 2012c. While industry continued to contribute financially towards the operation of the Blue Box program, municipalities struggled to cope with rising material management costs and became increasingly dependent on the government for financial assistance [36].

By 1999, the Blue Box program teetered on the brink of insolvency, necessitating that industry and municipal actors collaborate to develop a more equitable and sustainable recycling solution. In 2000, a number of packaging organizations and municipal representatives signed a memorandum of understanding with the MOE to work towards achieving a sustainable municipal recycling system CCME, 2009. The organization produced a report entitled "Achieving Sustainable Municipal Waste Diversion Programs in Ontario", which ultimately served as the precursor to the 2002 Waste Diversion Act CCME, 2009. The Ontario Waste Diversion Act (WDA) came into effect on June 27, 2002, and was designed to "promote the reduction, reuse and recycling of waste and to provide for the development, implementation and operation of waste diversion programs" Waste Diversion Act, 2002, c. 6, s. 1 .

The Act also lead to the creation of Waste Diversion Ontario, a non-crown corporation tasked with promoting and maintaining sustainable waste diversion programs for Blue Box materials, hazardous 


\section{Regulation}

Recycling and Composting of Municipal Waste

(O. Reg. 101/94)

Waste Audits and Waste Reduction Work Plans

(O. Reg. 102/94)

Industrial, Commercial and Institutional Source Separation Programs (O. Reg. 103/94)

Packaging Audit and Packaging Reduction Work Plans (O. Reg 104/94)

\section{Objective}

Every municipality with a population of 5,000 or more residents are obligated to operate a Blue Box program accepting at least five mandatory materials [32].

Designated organizations from the IC\&I sectors are required to conduct annual waste audits. A waste audit highlights the types of wastes that are produced, the manner in which wastes are produced, and in what quantities they are produced, within an organization [32].

Organizations must implement the use of a source separation program. As part of the source separation program, collection, handling and storage facilities mus be provided for recyclable materials. A business must make reasonable efforts to ensure that the system is used and that source separated materials are reused or recycled [32].

The regulation requires manufacturers, packagers and importers of packaged food, beverage, paper or chemical products to conduct a packaging audit and implement a packaging reduction work plan [32].

Table 2: 3R Regulations under the Waste Reduction Action Plan.

and special waste, waste electronics, and used tires. On September 23, 2002, Blue Box Waste became the first waste to be designated under the WDA. Stewardship Ontario was named as the Industry Funding Organization (IFO) for the Blue Box Program CCME, 2009. The Blue Box Program Plan (BBPP) was approved by the MOE on December 22, 2003 and went into operation on February 1, 2004. Under provincial regulation 274/04, all producers of printed paper and packaging would pay a fee to finance the end of life management of material generated in the province CCME, 2009. Producers were financially obligated to contribute $50 \%$ of reported municipal costs for the operation and maintenance of the Blue Box program. With this regulation, Ontario became the first province in Canada to implement an extended producer responsibility (EPR) scheme CCME, 2009.

Ontario's transition to an EPR scheme marked a shift in the cost of managing end of life products from the local tax base to packaging producers [37-39]. While its implementation was initially met with opposition from the packaging industry, the MOE remained steadfast in their desire to move towards a full "Polluter Pays" system Crittenden, 2006. To date, Ontario's partial EPR scheme remains the foundation for managing and financing the provincial Blue Box program. While Ontario's Blue Box system does an effective job in recycling and repurposing waste, numerous challenges exist to achieving a closed loop system. Coincidentally, these challenges are a direct result of how packaging producers have responded to the evolution of Ontario's MSWM systems. The fees charged to packaging producers as part of the province's EPR system are calculated on a per tonne basis. As such, many packaging producers have opted to switch to light weight packaging (namely LDPE, PET thermoforms and polystyrene crystal) to minimize the impact of the fee. The issue with this is twofold,

1) Consumers don't readily recognize these materials as being recyclable and

2) These items are voluminous but not very heavy. This not only results in less material being placed in the Blue Box, but lower tonnages (and thus, lower recycling rates) for the material that is collected. The impact of these changes have been significant, as Ontario's recycling rate stagnated at $68 \%$ in 2010 , and subsequently declined to $63 \%$ in 2012 Stewardship Ontario, 2013.

\section{A note on terminology}

This study sometimes uses the terms diversion, recycling and recovery interchangeably as it pertains to waste management activities in Ontario. The terms differ in their formal definitions and understanding when and why to use the terms is of particular importance. The United States Environmental Protection Agency (USEPA) defines recycling as "Using waste as material to manufacture a new product. Recycling involves altering the physical form of an object or material and making a new object from the altered material." (2014). similarly, the USEPA defines diversion as "the combined efforts of waste prevention, reuse, and recycling practices" (2014). All material recycled is by definition, diverted, but not all material diverted is recycled. With that being said, in Ontario, the terms recycling, diversion and recovery are, for all intents and purposes, the same for residential Blue Box waste. In order for a packaging product to be classified as diverted, it must be recycled into a new product. Ontario, unlike some other provincial jurisdictions (i.e. Nova Scotia and Quebec) does not recognize incineration as a diversion strategy for packaging waste. Thus, the policy vernacular in Ontario will often use diversion, recycling and recovery interchangeably when referring to Blue Box materials. Using these terms as substitutes for one another is not appropriate when discussing waste management activities in other jurisdictions, or when referencing the literature. What is meant by recycling and diversion will depend on site specific contexts and interpretations, and thus, caution should be used when using them.

\section{How has the generation and recovery of non-core materials changed over time?}

Using historical data from the Stewardship Ontario PIM model, Tables 3-5 below show how quantities of non-core Blue Box generation and recovery have changed over the past decade. For illustrative purposes, these figures are compared against how the generation and diversion of core materials have changed during this same period. Note: quantities of overall household waste generation in Ontario have actually decreased in the past decade. In 2002, the average Ontarian generated $383 \mathrm{~kg}$ of waste per year. This is compared to $366 \mathrm{~kg}$ per capita/per year estimated by the WDO in 2012. Some municipal officials have suggested that decreases in generation are not necessarily attributed to changes in household behavior, but due to the increasing shift towards light weight packaging by packaging producers. There is evidence to support these claims, as a review of steward sales data remitted to Stewardship Ontario indicates that the quantities of packaging waste sold into the market (expressed in terms of unit sales, not weight based metrics, i.e. tonnes) has increased over the past decade Stewardship Ontario.

From the above tables, we see that the both the generation and recovery of non-core materials has increased significantly over the past 10 years. Expressed as a percentage of overall Blue Box generation, noncore materials have increased from $7 \%$ to $11 \%$ of all material generated in the province. Conversely, the relative contribution of core materials, both with respect to overall generation and diversion (expressed as a $\%$ of the total number of tonnes being managed within the system) 


\begin{tabular}{|c|c|c|}
\hline Materials & \multicolumn{2}{|c|}{ Quantity Generated } \\
\hline Non-Core Materials & $\begin{array}{l}2003 \text { Quantity } \\
\text { Generated in T }\end{array}$ & $\begin{array}{l}2014 \text { Quantity } \\
\text { Generated in T }\end{array}$ \\
\hline Gable Top Cartons & $14,249 \mathrm{~T}$ & $42,000 \mathrm{~T}$ \\
\hline Paper Laminants & $2,800 \mathrm{~T}$ & $39,205 \mathrm{~T}$ \\
\hline Aseptic Containers & $5,820 \mathrm{~T}$ & $12,800 \mathrm{~T}$ \\
\hline Plastic Film & $53,700 \mathrm{~T}$ & $54,383 \mathrm{~T}$ \\
\hline Plastic Laminants & $35,391 \mathrm{~T}$ & $35,391 \mathrm{~T}$ \\
\hline Polystyrene & $20,400 \mathrm{~T}$ & $57,400 \mathrm{~T}$ \\
\hline Other Plastics & $28,300 \mathrm{~T}$ & $70,790 \mathrm{~T}$ \\
\hline Core Materials & $\begin{array}{l}2003 \text { Quantity } \\
\text { Generated in T }\end{array}$ & $\begin{array}{l}2014 \text { Quantity } \\
\text { Generated in T }\end{array}$ \\
\hline Newsprint - CNA/OCNA & $264,800 \mathrm{~T}$ & $217,375 \mathrm{~T}$ \\
\hline $\begin{array}{c}\text { Newsprint - Non-CNA/ } \\
\text { OCNA }\end{array}$ & $136,400 \mathrm{~T}$ & $148,405 \mathrm{~T}$ \\
\hline Magazines and Catalogues & $95,100 \mathrm{~T}$ & $78,908 \mathrm{~T}$ \\
\hline Telephone Books & $15,000 \mathrm{~T}$ & $8,329 \mathrm{~T}$ \\
\hline Other Printed Paper & $127,800 \mathrm{~T}$ & $128,245 \mathrm{~T}$ \\
\hline Corrugated Cardboard & $140,000 \mathrm{~T}$ & $169,361 \mathrm{~T}$ \\
\hline Boxboard & $130,500 \mathrm{~T}$ & $163,988 \mathrm{~T}$ \\
\hline PET Bottles & $36,200 \mathrm{~T}$ & $56,848 \mathrm{~T}$ \\
\hline HDPE Bottles & $23,000 \mathrm{~T}$ & $27,598 \mathrm{~T}$ \\
\hline $\begin{array}{l}\text { Steel Food \& Beverage } \\
\text { Cans }\end{array}$ & $57,800 \mathrm{~T}$ & $45,286 \mathrm{~T}$ \\
\hline Steel Aerosols & $4,300 \mathrm{~T}$ & $4,079 \mathrm{~T}$ \\
\hline Steel Paint Cans & $4,800 \mathrm{~T}$ & $5,072 \mathrm{~T}$ \\
\hline $\begin{array}{l}\text { Aluminum Food \& } \\
\text { Beverage Cans }\end{array}$ & $24,100 \mathrm{~T}$ & $22,552 \mathrm{~T}$ \\
\hline Other Aluminum Packaging & $2,408 \mathrm{~T}$ & $4,521 \mathrm{~T}$ \\
\hline Clear Glass & $76,200 \mathrm{~T}$ & $74,522 \mathrm{~T}$ \\
\hline Colored Glass & $6,700 \mathrm{~T}$ & $25,277 \mathrm{~T}$ \\
\hline
\end{tabular}

Table 3: Changes in generation of core and non-core Blue Box Packaging (Source: Stewardship Ontario PIM 2003-2015 PIM Model [34]).

is decreasing. While it is uncertain as to whether these trends will continue into the future, we can intuit the following.

\section{Results and Discussion}

\section{Graphing trends in generation, recovery, gross costs and revenue}

For each of the 9 material categories, graphs were created plotting how material generation, recovery, gross costs (per tonne) and revenue (per tonne) have changed over time. Where appropriate, best fit and $\mathrm{R}^{2}$ values were calculated and plotted to determine the strength of the trend given the data. Graphs for each of the 9 material categories outlined in Table 1 are shown below. A brief commentary explaining the general trends observed and potential short term trends are also offered.

Note: Net cost of material management is calculated by taking the gross cost of material management and subtracting revenue from the sale of marketed material. Revenue for each material is calculated using the twelve month average of the spot price received from the sale of material by provincial municipalities. Recycling rates are calculated by dividing the total quantities of material recovered by the total quantities of material generated.

Newsprint: The following can be surmised from examining Figures 1-22 below. Newsprint generation is trending down over time. This result has moderate statistical support and is consistent with the prevailing opinions on the subject (i.e. newsprint is a dying medium being replaced by electronic media). Newsprint recovery has remained relatively consistent over time, trending up very slightly. There is insufficient statistical support to say that newsprint recovery is likely to stay the same moving forward. Given decreases in newsprint generation, it seems plausible that newsprint recovery will actually begin to decrease in a future time period. Newsprint revenue has fluctuated over time, but remains relatively flat as a whole. There is no statistical support suggesting expected revenue increases or decreases over time. The effect of decreasing newsprint generation on material revenues is indeterminate at this time. Decreasing generation leads to increased scarcity for recyclable material (increasing revenue price signal). However, decreases in generation is indicative of a decrease in demand for the commodity as a whole (decreasing revenue price signal) Gross costs of material management for newsprint have increased significantly over time.

Mag, Tel and OPP: Magazines, telephone directories and Other Printed paper have experienced significant decreases in generation over the past decade (strong statistical support). This is once again consistent with the assumption that magazines and telephone are dated mediums. Recovery of these materials has remained relatively flat over time, although there is a minor kink point of inflection in the trend starting in 2012 that indicates decreased recovery over time. Realized revenue for magazines, directories and other printed paper has remained unchanged over the past decade. No discernable or statistically support trend exists indicating the future trend for revenue. Like with

\begin{tabular}{|c|c|c|}
\hline \multirow{2}{*}{$\begin{array}{c}\text { Category } \\
\text { Non-Core Materials }\end{array}$} & \multicolumn{2}{|c|}{ Quantity Recovered } \\
\hline & $\begin{array}{l}2003 \text { Quantity } \\
\text { Recovered in T }\end{array}$ & $\begin{array}{l}2014 \text { Quantity } \\
\text { Recovered in T }\end{array}$ \\
\hline Gable Top Cartons & $420 \mathrm{~T}$ & $6,833 \mathrm{~T}$ \\
\hline Paper Laminants & $268 \mathrm{~T}$ & $1,264 \mathrm{~T}$ \\
\hline Aseptic Containers & $1,222 \mathrm{~T}$ & $955 \mathrm{~T}$ \\
\hline Plastic Film & $2,993 \mathrm{~T}$ & $4,923 \mathrm{~T}$ \\
\hline Plastic Laminants & $574 \mathrm{~T}$ & $7 \mathrm{~T}$ \\
\hline Polystyrene & $541 \mathrm{~T}$ & $1,448 \mathrm{~T}$ \\
\hline Other Plastics & $1,603 \mathrm{~T}$ & $16,146 \mathrm{~T}$ \\
\hline Core Materials & $\begin{array}{l}2003 \text { Quantity } \\
\text { Recovered in T }\end{array}$ & $\begin{array}{l}2014 \text { Quantity } \\
\text { Recovered in T }\end{array}$ \\
\hline Newsprint - CNA/OCNA & $224,344 \mathrm{~T}$ & $203,689 \mathrm{~T}$ \\
\hline $\begin{array}{c}\text { Newsprint - Non-CNA/ } \\
\text { OCNA }\end{array}$ & $109,790 \mathrm{~T}$ & $139,062 \mathrm{~T}$ \\
\hline Magazines and Catalogues & $68,898 \mathrm{~T}$ & $61,776 \mathrm{~T}$ \\
\hline Telephone Books & $11,254 \mathrm{~T}$ & $7,968 \mathrm{~T}$ \\
\hline Other Printed Paper & $49,463 \mathrm{~T}$ & $57,949 \mathrm{~T}$ \\
\hline Corrugated Cardboard & $100,279 \mathrm{~T}$ & $144,539 \mathrm{~T}$ \\
\hline Boxboard & $54,712 \mathrm{~T}$ & $67,998 \mathrm{~T}$ \\
\hline PET Bottles & $18,120 \mathrm{~T}$ & $32,701 \mathrm{~T}$ \\
\hline HDPE Bottles & $11,551 \mathrm{~T}$ & $16,409 \mathrm{~T}$ \\
\hline $\begin{array}{c}\text { Steel Food \& Beverage } \\
\text { Cans }\end{array}$ & $30,447 \mathrm{~T}$ & $29,187 \mathrm{~T}$ \\
\hline Steel Aerosols & $1,008 \mathrm{~T}$ & $942 \mathrm{~T}$ \\
\hline Steel Paint Cans & $1,128 \mathrm{~T}$ & $696 \mathrm{~T}$ \\
\hline $\begin{array}{c}\text { Aluminum Food \& } \\
\text { Beverage Cans }\end{array}$ & $9,832 \mathrm{~T}$ & $10,860 \mathrm{~T}$ \\
\hline Other Aluminum Packaging & $282 \mathrm{~T}$ & $348 \mathrm{~T}$ \\
\hline Clear Glass & $40,336 \mathrm{~T}$ & $70,014 \mathrm{~T}$ \\
\hline Coloured Glass & $3,229 \mathrm{~T}$ & $17,210 \mathrm{~T}$ \\
\hline
\end{tabular}

Table 4: Changes in recovery of core and non-core Blue Box Packaging (Source: Stewardship Ontario PIM 2003-2015 PIM Model [34]). 


\begin{tabular}{|c|c|c|}
\hline Category & \multicolumn{2}{|c|}{ Recycling Rate } \\
\hline Non-Core Materials & $\begin{array}{l}2003 \text { Recycling Rate } \\
\text { in } \%\end{array}$ & $\begin{array}{l}2014 \text { Recycling Rate } \\
\text { in \% }\end{array}$ \\
\hline Gable Top Cartons & $2.95 \%$ & $16.27 \%$ \\
\hline Paper Laminants & $9.57 \%$ & $3.22 \%$ \\
\hline Aseptic Containers & $21 \%$ & $7.46 \%$ \\
\hline Plastic Film & $5.57 \%$ & $9.05 \%$ \\
\hline Plastic Laminants & $1.62 \%$ & $0.02 \%$ \\
\hline Polystyrene & $2.65 \%$ & $2.52 \%$ \\
\hline Other Plastics & $5.66 \%$ & $22.81 \%$ \\
\hline Core Materials & $\begin{array}{l}2003 \text { Recycling Rate } \\
\text { in \% }\end{array}$ & $\begin{array}{l}2014 \text { Recycling Rate } \\
\text { in \% }\end{array}$ \\
\hline Newsprint - CNA/OCNA & $84.72 \%$ & $93.70 \%$ \\
\hline Newsprint - Non-CNA/OCNA & $80.49 \%$ & $93.70 \%$ \\
\hline Magazines and Catalogues & $72.45 \%$ & $78.29 \%$ \\
\hline Telephone Books & $75.03 \%$ & $95.67 \%$ \\
\hline Other Printed Paper & $38.70 \%$ & $45.19 \%$ \\
\hline Corrugated Cardboard & $71.63 \%$ & $85.34 \%$ \\
\hline Boxboard & $41.92 \%$ & $41.47 \%$ \\
\hline PET Bottles & $50.06 \%$ & $57.52 \%$ \\
\hline HDPE Bottles & $50.22 \%$ & $59.46 \%$ \\
\hline Steel Food \& Beverage Cans & $52.68 \%$ & $64.45 \%$ \\
\hline Steel Aerosols & $23.44 \%$ & $23.09 \%$ \\
\hline Steel Paint Cans & $23.5 \%$ & $13.72 \%$ \\
\hline $\begin{array}{l}\text { Aluminum Food \& Beverage } \\
\text { Cans }\end{array}$ & $40.92 \%$ & $48.16 \%$ \\
\hline Other Aluminum Packaging & $11.71 \%$ & $7.7 \%$ \\
\hline Clear Glass & $52.93 \%$ & $93.95 \%$ \\
\hline Coloured Glass & $48.19 \%$ & $68.09 \%$ \\
\hline
\end{tabular}

Table 5: Changes in recycling rate of core and non-core Blue Box Packaging between 2003 and 2013 (Source: Stewardship Ontario PIM 2003-2015 PIM Model [34]).

newsprint, the effect of decreasing Mag, Tel and OPP generation over time on revenue is indeterminate. Gross costs of material management for Mag, Tel and OPP are trending up significantly over time.

OCC and OBB: Both the generation and recovery of corrugated cardboard and box board have increased significantly over time (moderate statistical support). However, a kink is observed in the recovery of OCC and OBB in 2010, with a downtrend established in the following three years. As such, no reasonable projections regarding the future recovery of OCC and OBB can be made Realized revenues for OCC \& OBB are increasing significantly over time (strong statistical support). Gross costs of material management are indeterminate, as a significant break in the trend occurs between 2012 and 2013 (fall in costs).

Composite packaging: Recovery of composite packaging has increased significantly over the past decade (extremely strong statistical support) and there is a reasonable expectation that this trend is likely to persist into the future. These increases in recovery may be attributed to new recycling capacity and end markets being developed for composite packaging. Generation of composite packaging is trending up slightly (weak statistical support) over time, although no projections can be reasonably made at this time. The realized revenue for composite packaging has increased significantly over time (see above reasons for explanation), with gross costs of material management remaining flat. A kink in the trend occurs between 2012 and 2013 that suggests a rise in gross costs, although additional observations need to be made before a trend emerges.

PET and HDPE: Both PET and HDPE generation and recovery are trending up significantly over time (strong statistical support).
This trend is likely to persist into the future. Revenues from the sale of PET have fluctuated significantly over time, although the trend for revenue as a whole appears to be slightly upward. No discernible future trend can be extrapolated given the existing data points and $\mathrm{R}^{2}$ values. Gross costs of material management for PET and HDPE have increased significantly over time (strong statistical support). While the drivers of these costs are unable to be identified at this time, this trend is projected to persist into the future.

Film, Lam, poly and other plastics: Both the generation and recovery of Film, Laminants, Polystyrene and Other Plastics is trending up significantly over time. This reflects an increasing trend by packaging producers to select light weight packaging like PET thermoforms, film and polystyrene crystal. This trend is likely to continue over time (strong statistical support) Revenues from the sale of Film, Lam, Poly and $\mathrm{OP}$ have increased materially over time, however, as observed with

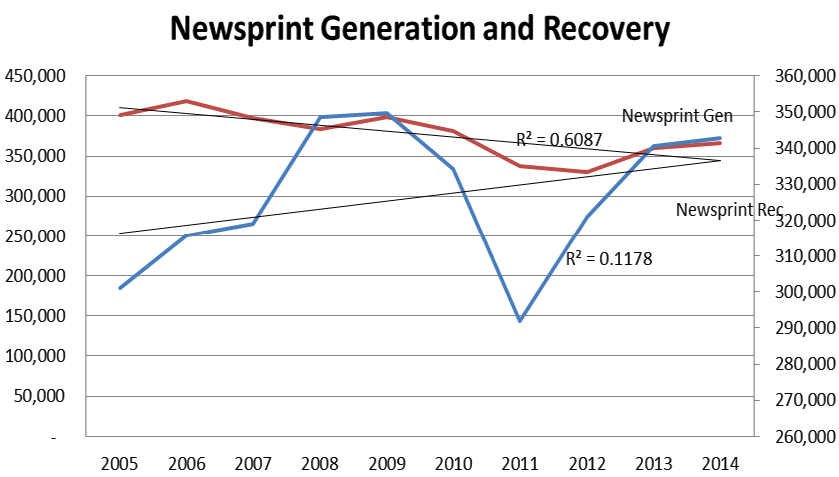

Figure 1: Newsprint Generation and Recovery.

\section{Newsprint Revenue and Gross Costs ( $T$ )}

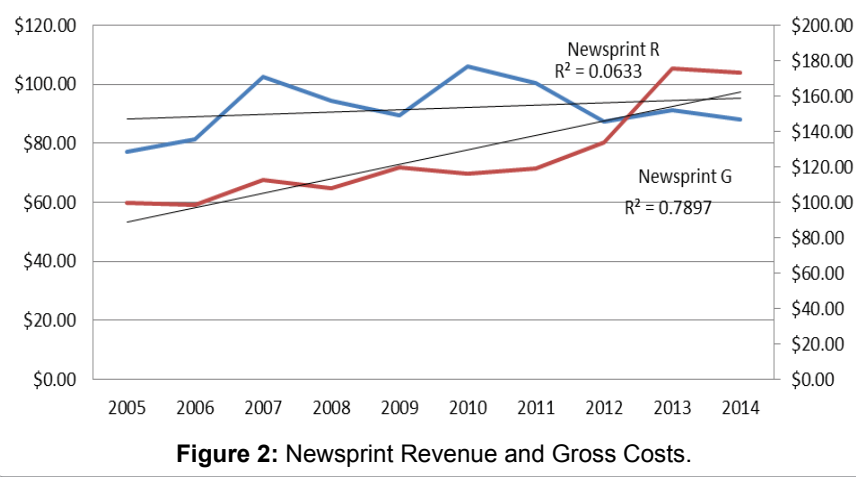

Mag, Tel, OPP Generation and Recovery

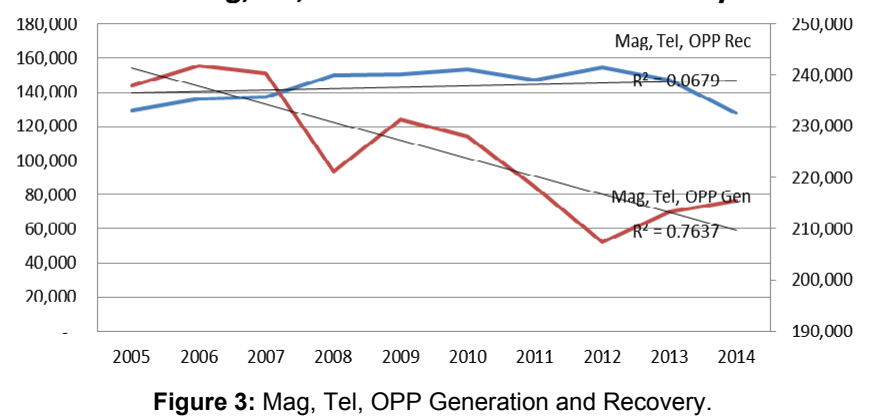


PET and HDPE plastics, revenue prices tend to be quite volatile. Gross costs of material management are trending up, although only weakly.

Steel: Both the generation and recovery of Steel is trending down over time (moderate statistical support). There is insufficient statistical evidence to project whether this trend is likely to persist. Realized revenue and gross cost of material management for steel have increased significantly over time. While there is strong statistical support to suggest that this trend is likely to continue, the reasons for these increases are not readily apparent at this time.

Aluminum: No discernible trend for the generation and recovery of aluminum was observed. While generation and recovery figures fluctuated significantly from year to year, when evaluated over the length of the study period, no material changes were observed. It should be noted that aluminum recovery will most likely be understated, as it is a target for scavengers who "pick" the material from residential blue boxes. Revenue for aluminum has also remained relatively flat over time, although commodity prices did spike significantly between 2009 and 2010. Gross costs of material management have trended up significantly over time (very strong statistical support).

Glass: Both the generation and recovery of glass have increased significantly over time (moderate to strong statistical support). Revenues for glass cullet have also trended up, although it should be noted that traditionally, glass is a low (no) value material that is commonly used in aggregate applications. While revenues have increased, it is not in any way that would have a significant impact on a municipalities net cost. Gross costs of material management have decreased slightly for glass cullet.

Summary comments on trends on material generation recover and cost of material management

While the above analysis is a first step in identifying how material recovery, generation and costs have changed over time, some salient findings are outlined below:

1) The assertion that rising system costs are attributable to decreases in material revenue is erroneous: In 8 of the 9 material categories, material revenues are either trending up over time or remaining flat.

2) More than $80 \%$ of increases in total system cost is attributable to increases in the gross cost of material management-costs that are independent of revenue

Plotting how overall Blue Box Composition and Recovery has changed

\begin{tabular}{|c|c|c|}
\hline $\begin{array}{c}\text { Blue Box Material } \\
\text { Categories }\end{array}$ & $\begin{array}{c}\text { \% Change Generation } \\
\mathbf{2 0 0 5 - 2 0 1 4} \text { in T }\end{array}$ & $\begin{array}{c}\text { \% Change Recovery } \\
\mathbf{2 0 0 5 - 2 0 1 5} \text { in T }\end{array}$ \\
\hline Newsprint & $-3.72 \%$ & $-4.06 \%$ \\
\hline Mag, Tel, OPP & $-2.30 \%$ & $-3.98 \%$ \\
\hline OCC \& OBB & $3.60 \%$ & $1.95 \%$ \\
\hline Composite Paper & $1.16 \%$ & $0.74 \%$ \\
\hline PET \& HDPE & $1.60 \%$ & $1.32 \%$ \\
\hline Film, Lam, Poly, OP & $1.07 \%$ & $1.72 \%$ \\
\hline Steel & $-1.08 \%$ & $-1.14 \%$ \\
\hline Aluminum & $-0.04 \%$ & $-0.17 \%$ \\
\hline Glass (clear and & $0.94 \%$ & $3.63 \%$ \\
\hline colored) & & \\
\hline
\end{tabular}

${ }^{1}$ Measured as change in percentage points

Table 6: Changes in Blue Box Material Generation and Recovery.
Mag, Tel, OPP Revenue and Gross Costs (T)

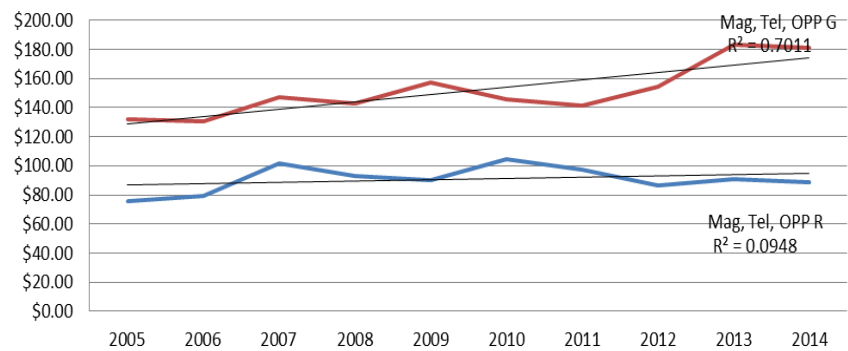

Figure 4: Mag, Tel, OPP Revenue and Gross Costs.

\section{OCC \& OBB Generation and Recovery}

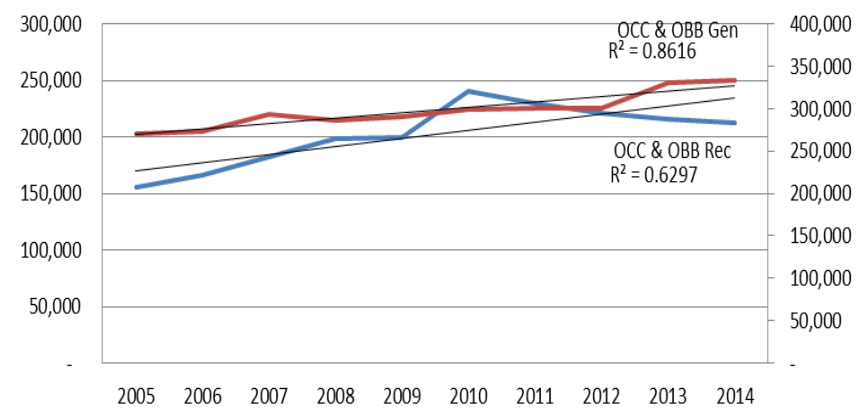

Figure 5: OCC and OBB Generation and Recovery.

OCC \& OBB Revenue and Gross Costs (T)

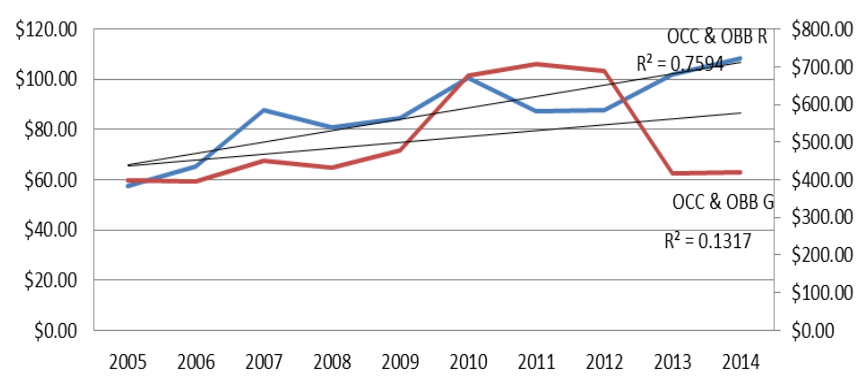

Figure 6: OCC and OBB Revenue and Gross Costs.

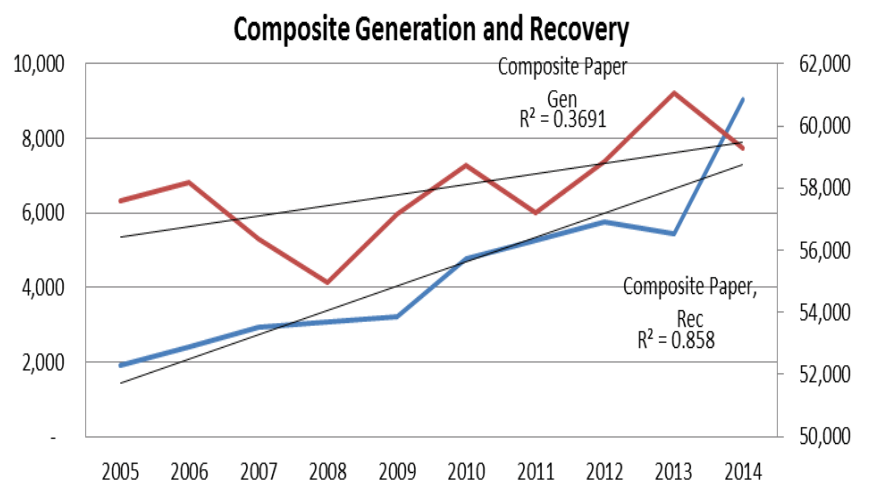

Figure 7: Composite Generation and Recovery. 


\section{Composite Revenue and Gross Costs (T)}

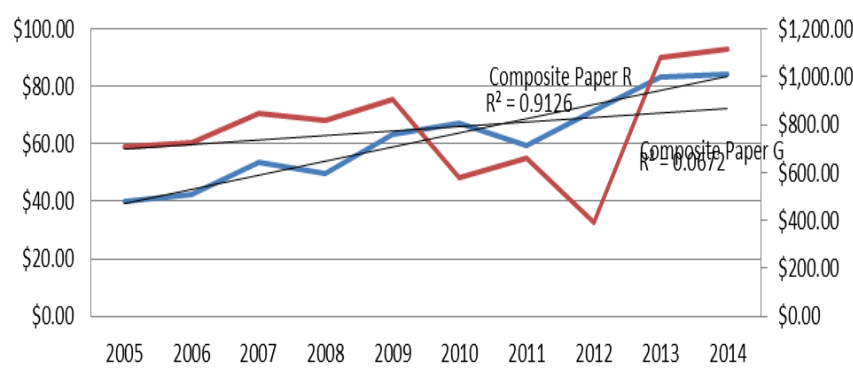

Figure 8: Composite Revenue and Gross Costs.

PET, HDPE Generation and Recovery

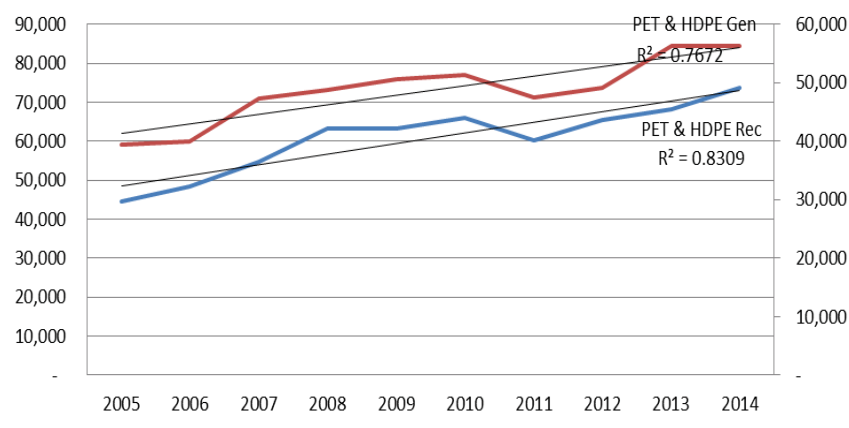

Figure 9: PET and HDPE Generation and Recovery.

PET \& HDPE Revenue and Gross Costs (T)

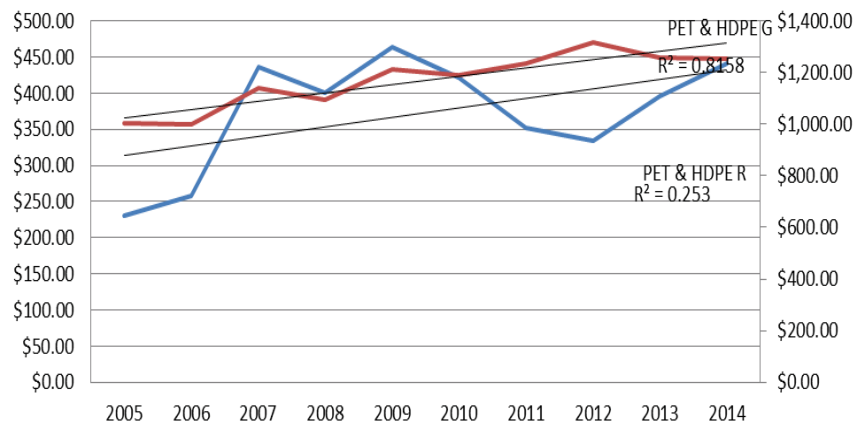

Figure 10: PET and HDPE Revenue and Gross Costs.

PET \& HDPE Revenue and Gross Costs (T)

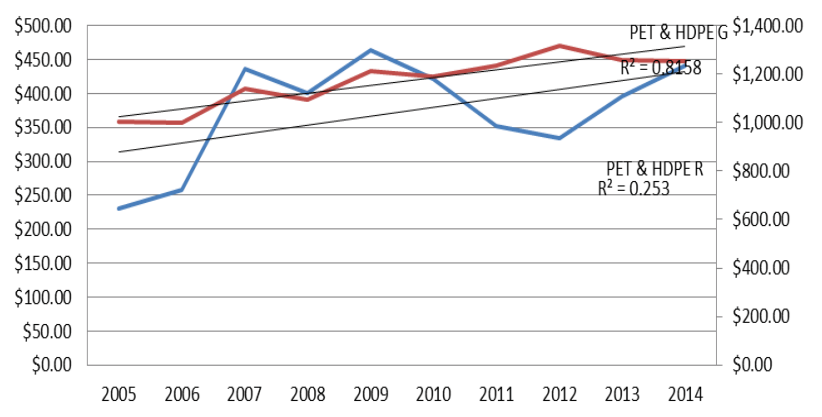

Figure 11: Film, Lam, Poly, OP Generation and Recovery.
Pie charts were graphed highlighting the relative contribution of each material category to the overall generation and recovery of Blue Box materials. For illustrative purposes, the years 2005 and 2014 are compared. The results of year over year changes are summarized in Table 6.

\section{Key findings:}

- Printed Paper is declining as a \% contribution to overall Blue Box generation and recovery

- Paper packaging is increasing as a \% contribution to overall Blue Box generation and recovery

- Plastics and Composite Paper are increasing as a \% contribution to overall Blue Box generation and recovery (the converse is observed for steel).

- Aluminum remain relatively unchanged with respect to their overall contribution to Blue Box Generation and Recovery

- The generation and recovery of light weight plastics such as Film, laminates and polystyrene has increased, while heavier materials such as telephone directories, newsprint and printed paper have decreased.

Note: The relative contribution to overall Blue Box generation and recovery may not change significantly over time for certain materials. This is due to the fact that they represent a small \% of the total tonnes being generated/managed within the system (i.e. composite materials), and thus, even large year over year changes in their recovery and generation are unlikely to affect the relative contribution to Blue Box tonnages as a whole.

Changes in Blue Box Component Costs: This section provides a high level overview of how Blue Box component and net costs have changed over the past 5 years. For the purposes of this discussion, component costs are defined as:

- Residential Collection Costs

- Residential Processing Costs

- Residential Depot/Transfer Station Costs

- Residential Promotion and Education Costs

- Administration Costs

- Interest on Municipal Capital

Changes in gross costs over time: In an attempt to identify how costs have changed for the Blue Box component categories, gross cost per tonne figures were graphed over time. Where appropriate, best fit lines and $\mathrm{R}^{2}$ values were calculated and applied to identify potential trends in the data. In Figure 23 below graphs how the costs for each of the Blue Box cost component categories have changed between 2008 and 2012. As shown above, each of the Blue Box cost component categories have increased each successive year between 2008 and 2012.

\begin{tabular}{|c|c|}
\hline \multicolumn{2}{|c|}{ 2008-2012 Change } \\
\hline Residential Collection Costs/T & $22 \%$ \\
\hline Residential Processing Costs/T & $23 \%$ \\
\hline Residential Depot/Transfer Costs/T & $49 \%$ \\
\hline Residential Promotion \& Education Costs/T & $30 \%$ \\
\hline Interest on Municipal Capital/T & $8 \%$ \\
\hline Administration Costs/T & $24 \%$ \\
\hline
\end{tabular}

Table 7: \% Cost Increases for each component cost category (2008-2012). 
Film, Lam, Poly, OP Revenue and Gross Costs (T)

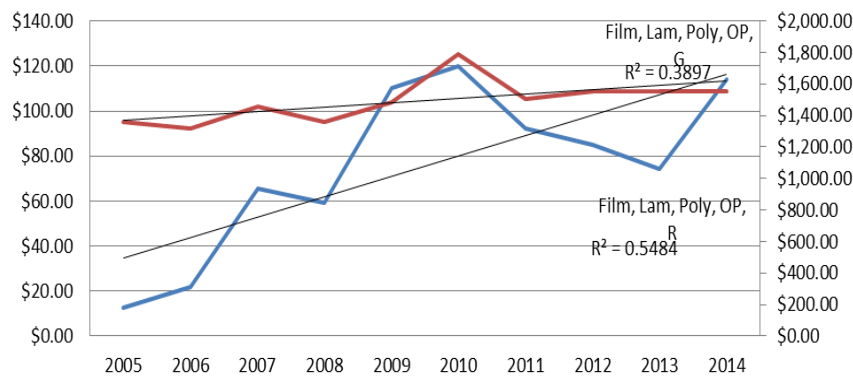

Figure 12: Film, Lam, Poly, OP Revenue and Gross Costs.

Steel Generation and Recovery

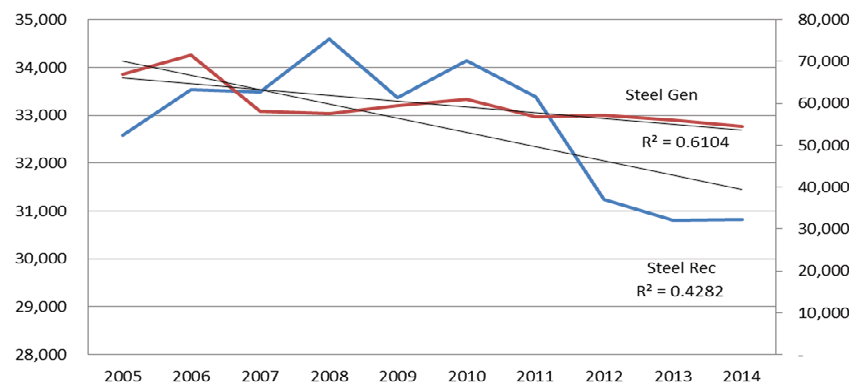

Figure 13: Steel Generation and Recovery.

Steel Revenue and Gross Costs ( $T$ )

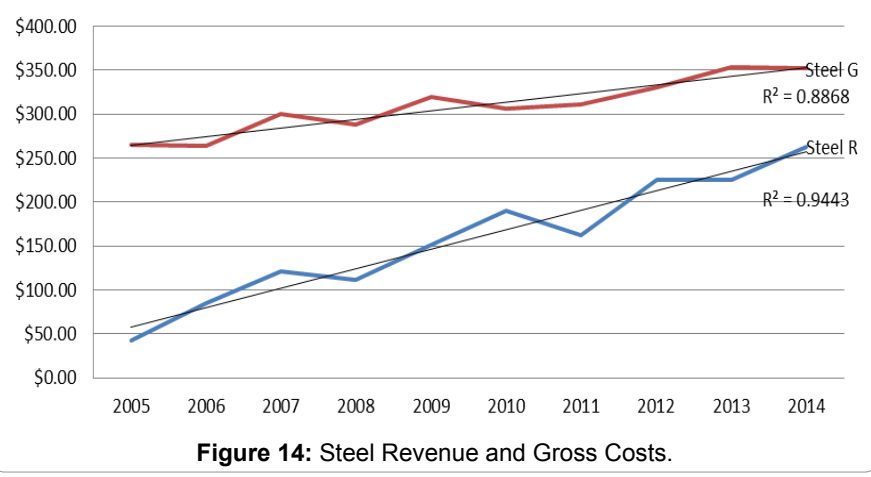

A best fit trend line was applied to the gross cost per tonne data points, resulting in an $\mathrm{R}^{2}$ of 0.94 and a positive slope of 14.06 Very strong relationship indicating upwards trajectory of gross costs. This would suggest that the gross costs of material management are expected to increase into the future. Table 7 summarizes the percentage cost increases for each of the cost component categories.

Relative contribution of costs: The relative contribution of each cost component category to total reported gross costs was calculated and graphed in an attempt to determine whether a certain cost category (i.e. residential collection costs) are driving costs more/less relative to other categories. In Figures 24 and 25 below graphs the relative contribution of each of the Blue Box component cost categories to the total gross cost between 2008 and 2012 (measured on a per tonne basis). Note: The data range is limited to these years as that is the only information that is made publicly available at this time. While the results in Table 7 seemingly suggest that there are differences in the percentage increase of costs for each of the cost component categories between 2008 and
2012, the above pie charts show that the relative contribution of said categories to the total gross costs remains unchanged. This is because two of the cost component categories Collection and processing accounts for nearly $86 \%$ of the total gross material management costs. Thus, even significant changes in the cost of administration or promotion and education are unlikely to affect the relative breakdown of costs as a whole.

Changes in revenue and net cost per tonne: Revenue figures for municipalities were calculated and graphed to determine how changes in revenue have affected the net cost per tonne over the past 5 years. As shown in Figure 26, net cost per tonne and revenue received from the sale of material has fluctuated over time. While net costs per tonne appear to be trending up over time possibly in part due to the rising gross costs of material management, the significance calculation was too low to draw any meaningful inferences. These data points were also plotted against the total amount of material marketed by municipalities

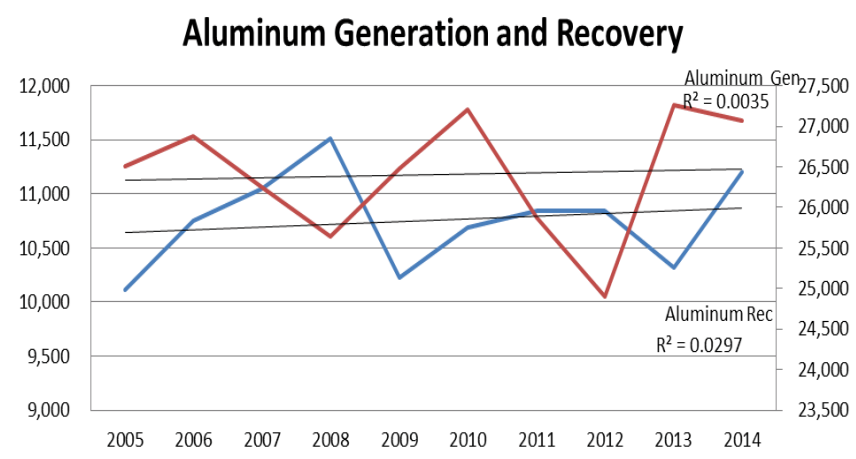

Figure 15: Aluminum Generation and Recovery.

Aluminum Revenue and Gross Costs ( $T$ )

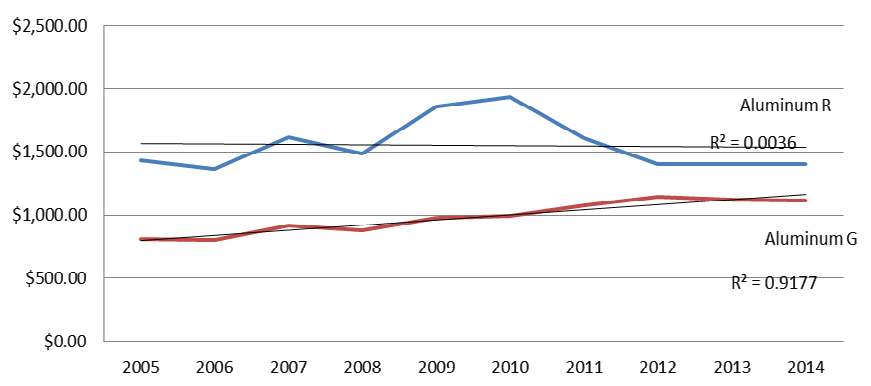

Figure 16: Aluminum Revenue and Gross Costs.

\section{Glass Generation and Recovery}

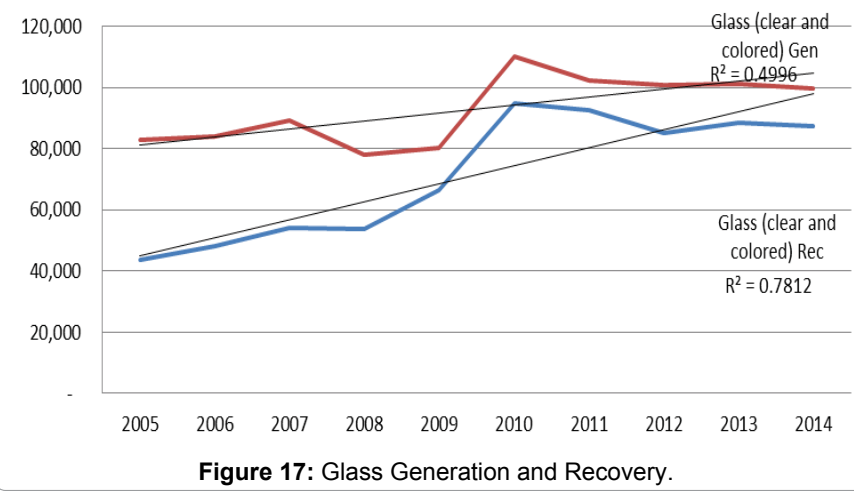




\section{Glass (Clear and Colored) Revenue and Gross} Costs (T)

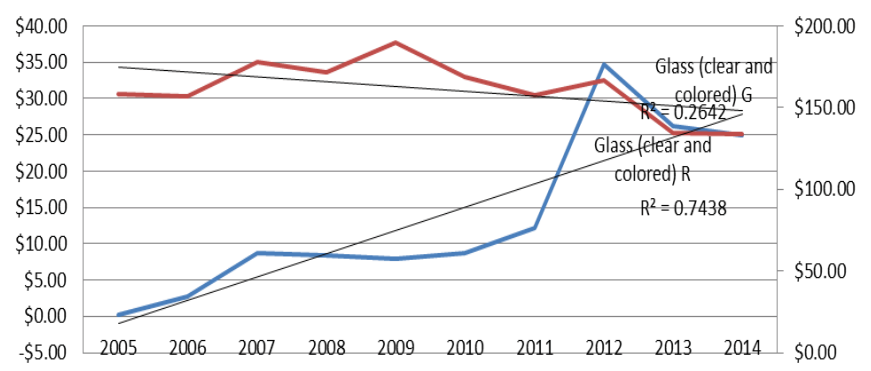

Figure 18: Glass Revenue and Gross Costs.

\section{Material Generation}

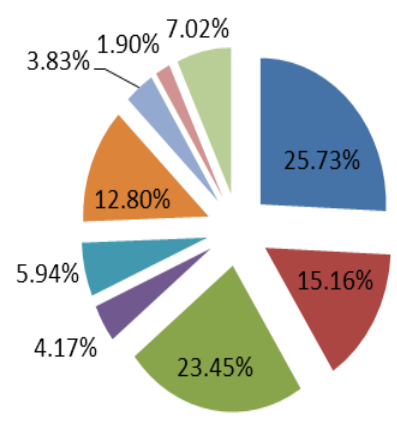

Newsprint
Mag, Tel, OPP
OCC \& OBB
Composite Paper
PET \& HDPE
Film, Lam, Poly, OP
Steel
Aluminum

Figure 19: Breakdown of 2014 material generation.

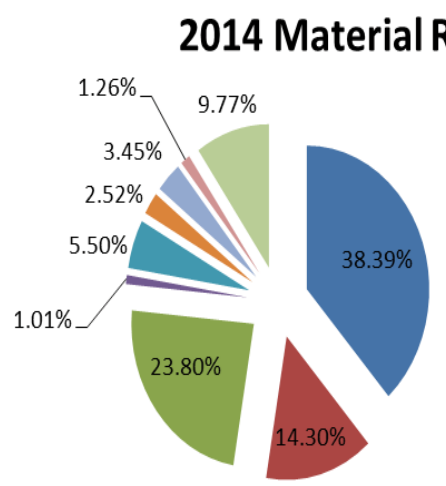

- Newsprint
Mag, Tel, OPP
- OCC \& OBB
- Composite Paper
- PET \& HDPE
- Film, Lam, Poly, OP
- Steel
- Aluminum

Figure 20: Breakdown of 2014 material recovery.

for each of the 5 years included in this study. Once again, while the total number of tonnes marketed has decreased over the past 5 years, no definitive trend could be established. Of note, the years 2009 and 2010 are generally considered outliers relative to a normal operating year. The economic recession of ' 09 , followed by the subsequent recovery in ' 10 , resulted in radical swings in the amounts of material generated, recovered and the revenues received by municipalities. Inclusion of these two years in the data set may obscure the overall trends for revenue, tonnes marketed and net costs. However, when weighed against the issues that arise from omitting these two years from the data set, the decision was made to include all years in the analysis.

Individual material management costs were also analyzed in an attempt to (in part) explain the changes observed in component category costs over time. Some salient findings include: Collection, Processing, Depot, Administrative, P\&E and Interest costs are increasing over time. However, the relative contribution of each of the above cost categories to gross cost remains unchanged. Revenue received and (and thus, net cost of material management) is fluctuating over time. There is no statistical support to comment definitively on the trends for revenue and net cost. Total quantities of Blue Box material being managed by the system is also fluctuating over time. While total units of packaging sold/generated into the province has increased over the past decade, using strictly weight based metrics tonnes to measure overall generation reveals no definitive trend. With this in mind, we must consider why the gross costs of material management are increasing, and place it within the context of changes to the recycling system as a whole. Changes in the types of material being generated and recovered have been cited as a primer driver of component costs over the past 5 years.

Changes in the packaging mix: Using historical data from the Stewardship Ontario PIM model, Tables 3-5 below show how quantities of non-core Blue Box generation and recovery have changed over the past decade. For illustrative purposes, these figures are compared against how the generation and diversion of core materials have changed during this same period. Note: quantities of overall household waste generation in Ontario have actually decreased in the past decade. In 2002, the average Ontarian generated $383 \mathrm{~kg}$ of waste per year. This is compared to $366 \mathrm{~kg}$ per capita/per year estimated by the WDO in 2012 and WDO 2014. Some municipal officials have suggested that decreases in generation are not necessarily attributed to changes

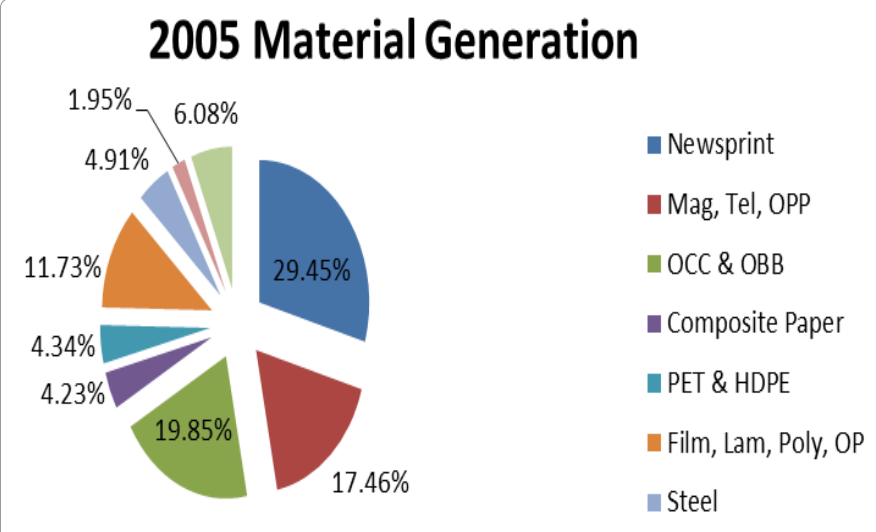

Figure 21: Breakdown of 2005 material generation.

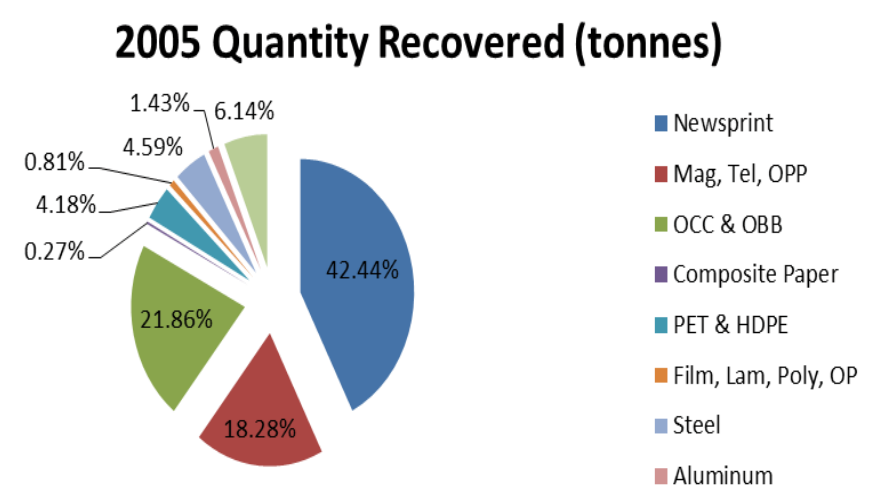

Figure 22: Breakdown of 2005 material recovery. 
Gross Cost Component Trends Over Time (20082012)

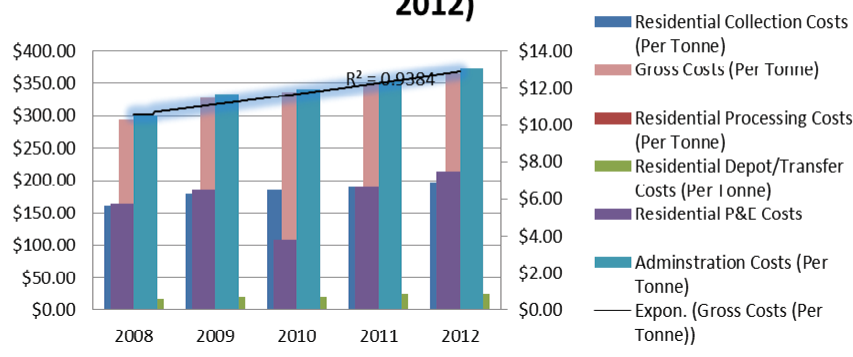

Figure 23: Gross Cost Component Trends over Time.

\section{Breakdown of Recycling Costs (Per Tonne) (2008)}

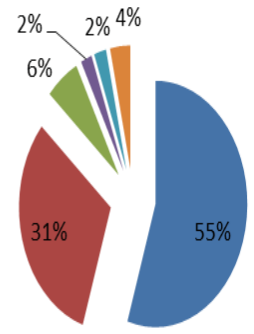

\author{
- Residential Collection Costs (Per \\ Tonne) \\ Residential Processing Costs (Per \\ Tonne) \\ Residential Depot/Transfer Costs \\ (Per Tonne) \\ Residential Promotion \& \\ Education Costs (Per Tonne) \\ Interest on Municipal Capital (Pe \\ Tonne) \\ Adminstration Costs (Per Tonne)
}

Figure 24: Breakdown of Recycling Costs (2008).

\section{Breakdown of Recycling Costs (Per Tonne)}

$$
\text { (2012) }
$$

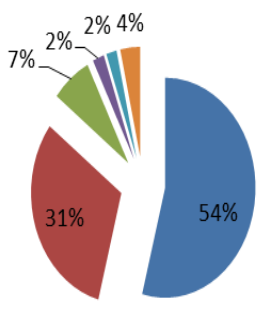

$$
\begin{aligned}
& \text { Residential Collection Costs (Per } \\
& \text { Tonne) } \\
& \text { Residential Processing Costs (Per } \\
& \text { Tonne) } \\
& \text { Residential Depot/Transfer Costs } \\
& \text { (Per Tonne) } \\
& \text { Residential Promotion \& } \\
& \text { Education Costs (Per Tonne) } \\
& \text { Interest on Municipal Capital (Per } \\
& \text { Tonne) } \\
& \text { Adminstration Costs (Per Tonne) }
\end{aligned}
$$

Figure 25: Breakdown of Recycling Costs.

in household behavior, but due to the increasing shift towards light weight packaging by packaging producers. There is evidence to support these claims, as a review of steward sales data remitted to Stewardship Ontario indicates that the quantities of packaging waste solid into the market expressed in terms of unit sales, not weight based metrics, i.e. tonnes has increased over the past decade Stewardship Ontario, 2013. From the above tables, we see that the both the generation and recovery of non-core materials has increased significantly over the past 10 years. Expressed as a percentage of overall Blue Box generation, non-core materials have increased from $7 \%$ to $11 \%$ of all material generated in the province. Conversely, the relative contribution of core materials, both with respect to overall generation and diversion expressed as a $\%$ of the total number of tonnes being managed within the system is decreasing. While it is uncertain as to whether these trends will continue into the future, we can intuit the following:

- The generation and recovery of printed paper (newsprint, magazines and telephone directories etc) is trending down (expressed in absolute tonnes). This is consistent with the prevailing opinion by packaging producers that printed paper is a dying medium increasingly being replaced by electronic media. Given that printed paper comprises a significant portion of the existing Blue Box recycling stream (and is classified as a core material), it seems plausible that the generation and recovery of core materials will decrease over time.

- There is an increasing trend for producers to select light weight packaging to decrease transportation and logistics costs. Given that most light weight packaging is comprised of "non-core" materials (i.e. PET thermoform packaging, polystyrene crystal etc.), it is likely that the generation of non-core materials will continue to increase.

\section{Conclusion}

This study undertook an extensive overview of the state of recycling in Ontario, including detailed discussions on the types of material being generated and diverted and the economics of Blue Box recycling. Specifically, this study examined how Blue Box generation, recovery and costs have changed over time, and identified trends in the data to suggest that material management costs are increasing inordinately relative to the quantities of material being recovered. While it is difficult to specifically isolate the cause for rising system costs, there is evidence in the data to suggest that high cost "fringe" materials now comprise a larger share all material being generated in the province. Given that there is strong statistical support to suggest that this trend is likely to continue into the future, policy planners need to take a step back and identify not only how to reverse these trends, but develop policies that optimize the mix of materials being recovered. While increased recycling should continue to be a policy priority, we need to recognize that the most sustainable recycling system isn't necessarily the one that diverts the most material. Much of the current dialogue surrounding waste management revolves around increasing recycling rates and diversion levels; one must take a step back and ask whether a higher recycling rate should be the focal point of policy objectives. Are there metrics beyond recycling rates that need to be considered when evaluating the long term sustainability of waste management systems? A recycling system that does not encourage cost containment cannot be considered tenable in the long run. Though recycling is a central component of developing sustainable waste management systems, its adoption must be weighed against budgetary, social and environmental considerations. The careful balancing act between continuous improvement in diversion and cost containment is a topic that requires increased academic attention.

Though the above analysis offers some very tentative explanations for rising material management costs as a whole, it does little to explain

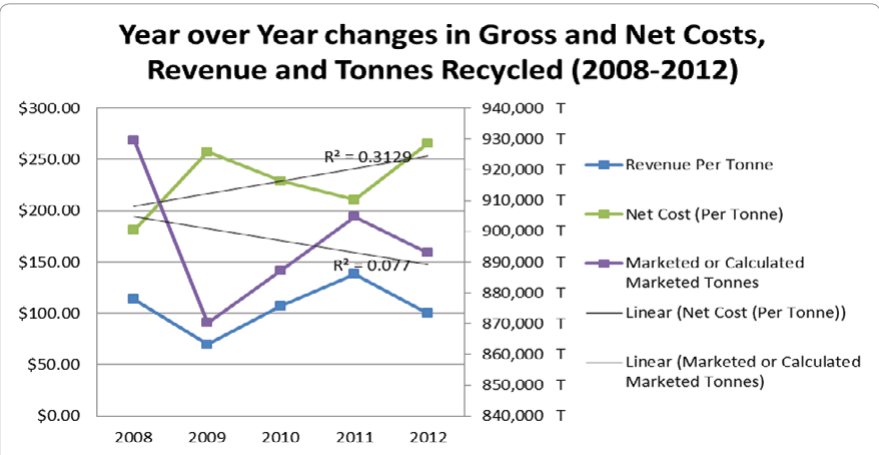

Figure 26: Changes in Gross and Net Costs, Revenues and Tonnes Recycled, 2008-2012. 
the increases in cost for individual cost component categories. Why does changing the types of material being recovered increase collection or administration costs? Are there drivers of cost being omitted from the aforementioned analysis that better explain why costs have changed the way they have? Answering these questions necessitates significant additional research and analysis.

\section{References}

1. Babooram A, Wang J (2008) Recycling In Canada. Statistics Canada Publications.

2. Waste Diversion Ontario (2014) Blue Box Tonnage Highlights and Summary.

3. Waste Diversion Ontario (2014) 2012 Ontario Residential Diversion Rates.

4. Stewardship Ontario (2007) Blue Box program enhancement and best practice assessment project.

5. Lavee D (2007) Is municipal solid waste recycling economically efficient Environmental Management 40: 926-943.

6. Bohm RA, Folz DH, Kinnaman TC, Podolsky MJ (2010) The Costs of Municipal Waste and Recycling Programs. Resources Conservation and Recycling 54: 864-871.

7. Staudt $E$ (1993) A comparison of the cost structure and fees for domestic waste disposal and recycling abridged version Ruhr Universitat, Bochum, Germany.

8. Ready M, Ready R (1994) Optimal pricing of depletable, replaceable resources: The case of landfill tipping fees, Journal of Environment and Economic Management 28: 307-323.

9. Brisson IE (1997) Assessing the waste hierarchy: A social cost benefit analysis of municipal solid waste management in the European Union 19 AKF Forlaget, Kopenhagen.

10. Podolsky MJ, Spiegel M (1998) Municipal waste disposal: Unit pricing and recycling opportunities. Public Works Management Policy 3: 27-39.

11. Jenkins R (1993) The Economics of Solid Waste Reduction: The Impact of User Fees, Edward Elgar Publishing: London, UK.

12. Kinnaman $T$ (2006) Examining the justification for residential recycling. Journal of Economic Perspectives 20: 219-232.

13. Kinnaman T (2008) The Economics of Municipal Solid Waste Management Waste Management 29: 2615-1617.

14. Allers M, Hoebin C (2010) Effects of unit based garbage pricing: A differences in differences approach. Environmental Resource Economics 45: 405-428.

15. Palatnik R, Ayalon O, Shechter M (2005) Household demand for waste recycling services. Journal of Environmental Management 35:121-129.

16. Lakhan C (2016) The relationship between municipal waste diversion incentivization and recycling rate performance: An Ontario case study. Resources Conservation and Recycling 106: 68-77.

17. Lakhan C (2014) Exploring the relationship between municipal promotion and education investments and recycling rate performance: An Ontario case study. Resources Conservation and Recycling 11: 222-229.

18. Miranda M, Everett J, Blume D, Barbeau R (1994) Market based incentives and residential municipal solid waste. Journal of Policy Analysis and Management 13: $681-698$
19. Harder MK, Woodard R, Bench ML (2006) Two measured parameters correlated to participation rates in curbside recycling schemes in the U.K. Environmental Management 37: 487-495.

20. USEPA (2007) Municipal Solid Waste in the United States 2007 Facts and Figures. USEPA: Washington, United States.

21. Stewardship Ontario (2011) Blue Box GHG Report: Emissions Impact of Ontario's Blue Box Program.

22. Highfill J, Mcasey M (1997) Municipal Waste Management: Recycling and Landfill Space Constraints. Journal of Urban Economics 41: 118-36.

23. Conference Board of Canada (2014) Opportunities for Ontario's Waste: Economic Impacts of Waste Diversion in North America.

24. Munger M (2007) Think globally, act irrationally: Recycling, Library of Economics and Liberty.

25. Kinnaman TC, Fullerton D (1995) Garbage, Recycling, and Illicit Burning or Dumping. Journal of Environmental and Economic Management 29: 78-91.

26. Lah TJ (2002) The Critical Review of the Cost-Benefit Analysis in the Literature on Municipal Solid Waste Management. International Journal of Public Administration 7: 137-145.

27. Hostovsky C (2006) The Paradox of the Rational Comprehensive Model of Planning: Tales from Waste Management Planning in Ontario, Canada. Journa of Planning Education and Research, 25: 382-395.

28. Marques RC, da Cruz NF, Simões P, Ferreira S, Cabral M, et al. (2014 Economic viability of packaging waste recycling systems: a comparison between Belgium and Portugal. Resources Conservation and Recyling 85: 22-33.

29. Pingsha $H$ (2004) Environmental and economic benefit of recycling model of packaging waste: a case study on aluminum. Chinese Journal of Population, Resources and Environment 2: 30-36.

30. Stewardship Ontario (2005-2015) Pay in Model.

31. Ministry of the Environment (2004) Ontario Environmental Protection Act: Ontario Regulation 274/04 Tax Matters-Notice Under Subsection 365.1.

32. Ministry of the Environment (2011) Ontario Environmental Protection Act: Ontario Regulation 101/94 Recycling and Composting of Municipal Waste.

33. Beck RW (2001) U.S Recycling Economic Information Study National Recycling Coalition Inc.

34. Stewardship Ontario (2003-2015) Blue Box Annual Report.

35. McRobert D (1994) Ontario's Blue Box System: A Case Study of Government's Role in the Technological Change Process, 1970-1991. Osgoode Hall Law School, York University.

36. Menzies D (1997) Waste Blues-Curbside Recycling Reassessed. The Financia Post Magazine. September, 1997.

37. Deutz P (2009) Producer responsibility in a sustainable development context Ecological modernisation or industrial ecology?. The Geographical Journal 175: 274-285.

38. Kinnaman TC (2009) The economics of municipal solid waste management Waste Management 29: 2615-2617.

39. United States Environmental Protection Agency (2012) Municipal solid waste generation, recycling and disposal in the United States: Facts and Figures. 